\title{
SPOCK1 promotes the proliferation, migration and invasion of glioma cells through PI3K/AKT and Wnt/ק-catenin signaling pathways
}

\author{
JINGHUI YANG ${ }^{1}$, QIWEI YANG ${ }^{2}$, JING YU $^{3}$, XIMENG LI $^{4}$, SHAN YU $^{5}$ and XUEWEN ZHANG ${ }^{1}$ \\ ${ }^{1}$ Department of Hepatopancreatobiliary Surgery, China-Japan Union Hospital, Jilin University, Changchun, \\ Jilin 130033; ${ }^{2}$ Central Laboratory, Second Hospital, Jilin University, Changchun, Jilin 130041; \\ ${ }^{3}$ Department of Nephrology, China-Japan Union Hospital, Jilin University, Changchun, Jilin 130033; \\ ${ }^{4}$ Central Laboratory, College of Basic Medical Sciences, Jilin University, Changchun, Jilin 130012; \\ ${ }^{5}$ Department of Neurology, China-Japan Union Hospital, Jilin University, Changchun, Jilin 130033, P.R. China
}

Received December 21, 2015; Accepted January 30, 2016

DOI: $10.3892 /$ or.2016.4757

\begin{abstract}
Sparc/osteonectin, cwcv and kazal-like domains proteoglycan (testican) 1 (SPOCK1) has been reported to promote the growth and progression of various tumors. In this study, we focus on assessing the effect of SPOCK1 on proliferation, migration and invasion in glioma cells and elucidating its related mechanisms. The results of our present study demonstrated that overexpression of SPOCK1 promoted the proliferation and inhibited apoptosis in glioma cells. Additionally, overexpression of SPOCK1 promoted the migration and invasion potential of glioma cells. Moreover, we demonstrated that PI3K/AKT and Wnt/ $\beta$-catenin signaling pathways were activated by SPOCK1 overexpression. SPOCK1 silencing has precisely the opposite effect. In conclusion, our study suggests that SPOCK1 promotes proliferation, migration and invasion in glioma cells by activating PI3K/AKT and Wnt/ $\beta$-catenin pathways, which provides a potential theoretical basis for clinical treatment of glioma.
\end{abstract}

\section{Introduction}

Brain glioma, the most common primary brain tumor is thought to be one of the deadliest forms of cancer and over $2 / 3$ of the patients were diagnosed with malignant glioma (1).

Correspondence to: Dr Xuewen Zhang, Department of Hepatopancreatobiliary Surgery, China-Japan Union Hospital, Jilin University, 126 Xiantai Street, Changchun, Jilin 130033, P.R. China E-mail: xuemen_zh2008@126.com

Dr Shan Yu, Department of Neurology, China-Japan Union Hospital, Jilin University, 126 Xiantai Street, Changchun, Jilin 130033, P.R. China

E-mail: shan_yu2011@163.com

Key words: SPOCK1, glioma, proliferation, migration, invasion, PI3K/AKT, Wnt/ $\beta$-catenin
In the last twenty years, although the surgical techniques and treatment strategy have been greatly improved, the prognosis of patients with malignant glioma is still poor $(2,3)$. The oneyear survival rate of glioma is $<30 \%$ (4). The main biological characteristics of glioma is invasive growth, which results in incomplete surgery, high rate of recurrence and short survival period $(5,6)$. As the understanding of tumor mechanism has improved, the incidence and development of glioma is considered the result of interactions among various abnormally expressed genes. Thus, finding genes related to growth and invasiveness of glioma and revealing the possible mechanism has significant meaning in treatment of glioma.

SPOCK1, an oncogene, is frequently overexpressed in various cancer tissues (7). Increasing evidence has demonstrated that SPOCK1 plays important roles in proliferation, migration and invasion of tumor cells. Study by Miao et al showed that SPOCK1 as a target gene of TGF- $\beta 1$ could regulate lung cancer cell epithelial-mesenchymal transition and silencing of SPOCK1 obviously inhibited the proliferation and invasion of lung cancer cells (8). Previous study also found that SPOCK1, upregulated by CHD1L, promoted proliferation and invasion of hepatoma carcinoma cells (9). SPOCK1 was able to promote proliferation and metastasis of gallbladder cancer cells trough the PI3K/AKT signaling pathway (10). The expression levels of SPOCK1 in malignant glioma and pilocytic astrocytoma exhibited significant differences (11), which indicated that SPOCK1 had important effect on genesis and progression in glioma. However, the effect of SPOCK1 on proliferation and invasion of glioma cells and the underlying mechanisms are far from clear.

In this study, we investigated the effect of SPOCK1 on the proliferation, apoptosis, migration and invasion through overexpressing exogenous and RNA-interfered endogenous SPOCK1 expression in glioma cells.

\section{Materials and methods}

Cell lines and culture. The glioma cell line U251 and U87 MG cells were obtained from Type Culture Collection of Chinese 
Academy of Sciences and American Type Culture Collection, respectively. The U251 cells were maintained in DMEM (Gibco, Carlsbad, CA, USA). The U87 MG cells were cultured in MEM (Gibco). All the cells were supplemented with $10 \%$ fetal bovine serum (Hyclone, Logan, UT, USA), $100 \mu \mathrm{g} / \mathrm{ml}$ streptomycin and $100 \mathrm{U} / \mathrm{ml}$ penicillin (Hyclone), cultured at $37^{\circ} \mathrm{C}$, in a humidified environment of $5 \% \mathrm{CO}_{2}$ atmosphere.

Construction of plasmids and generation of stable cell lines. The sequences of SPOCK1 shRNA and negative control (NC) shRNA were 5'-GUAAUGAGGAGGGCUAUUA-3' and 5'-TTCTCCGAACGTGTCACGT-3', respectively. The sh-SPOCK1 and sh-NC were cloned into pGCsi-H1 vector (Genechem, Shanghai, China) separately and transfected into U87 MG cells. The human full-length cDNA of SPOCK1 was inserted into pEGFP-N1 vector (Clontech, San Jose, CA, USA) and transfected into U251 cells. Control cells were transfected with pEGFP-N1 vector. After transfection for $24 \mathrm{~h}, 400 \mu \mathrm{g} / \mathrm{ml}$ G418 was added into U87 MG and U251 cells for 2 weeks to select stable SPOCK1-silencing/overexpressing clones. The mRNA and protein expression levels of SPOCK1 were determined by qPCR and western blotting.

Antibodies and western blotting. Rabbit anti-cleaved caspase-3 (1:1000), anti-cleaved PARP (1:1000) antibodies were purchased from Abcam (MA, USA). Rabbit anti-Bax (1:400), anti-Bcl-2 (1:400), anti-PI3K (1:400), anti- $\beta$-catenin (1:400), anti-MMP2 (1:400), anti-MMP9 (1:400), mouse anti-c-MYC (1:200), anti-cyclin D1 (1:400) were obtained from Boster (Wuhan, China). Mouse anti-SPOCK1 (1:200), rabbit antip-AKT (1:200), anti-AKT (1:200), anti-Wnt (1:200) were obtained from Santa Cruz Biotechnology (Santa Cruz, CA, USA). Rabbit anti-p-PI3K (1:500) were obtained from Bioss (Beijing, China). Briefly, the cells were lysed in RIPA and then denatured. The protein concentration was measured using the BCA protein estimation kit (Beyotime, Shanghai, China). Protein samples were separated on an SDS-polyacrylamide gel and transferred to PVDF membranes. The membranes were blocked with 5\% non-fat dry milk in PBS for $2 \mathrm{~h}$ at room temperature, and incubated with primary antibodies, respectively, at $4^{\circ} \mathrm{C}$ overnight. After incubation with a secondary antibody the blots were visualized by ECL detection reagent (Beyotime).

Quantitative real-time polymerase chain reaction ( $q P C R)$. Quantitative PCR was used to quantify the expression of mRNA in cultured cells. Briefly, total RNA was extracted with TRIzol reagent (Invitrogen, Carlsbad, CA, USA). The total RNA $(1 \mu \mathrm{g})$ was reverse transcribed by a reverse transcriptase (Takara, Shiga, Japan). RNA expression was measured by qRT-PCR using the SYBR-Green method (Takara) according to the manufacturer's instructions. The primer sequences of SPOCK1 were as follows: SPOCK1 (forward, 5'-CACTG GGTTGGACCTTCGA-3'; reverse, 5'-CTTTGGTGGCTC AGGCTCT-3') and $\beta$-actin (forward, 5'-CTTAGTTGCGTT ACACCCTTTCTTG-3'; reverse, 5'-CTGTCACCTTCAC CGTTCCAGTT T-3'). $\beta$-actin was used as an internal reference gene to normalize the expression of detection genes. Relative quantification of gene was analyzed by the comparative threshold cycle $(\mathrm{Ct})$ method.
Cell proliferation assay. Cell proliferation was determined by Cell Counting Kit-8 (CCK8) (Beyotime, Shanghai, China). Cells were seeded into 96 -well plates $\left(3 \times 10^{3}\right.$ per well) and incubated for $24,48,72,96 \mathrm{~h}$, respectively. After incubation, $10 \mu \mathrm{l}$ of CCK8 reagent was added to each well and at $450 \mathrm{~nm}$ the absorbance was detected by a microplate reader (Bio-Tek, Winooski, VT, USA). The results represent three independent experiments.

Flow cytometry for cell cycle analysis. For the cell cycle assay, the cells in exponential growth period were collected, washed twice with cold PBS, fixed in cold $70 \%$ ethanol at $-20^{\circ} \mathrm{C}$. After washing with cold PBS the cells were incubated with $10 \mathrm{mg} / \mathrm{ml}$ Rnase A (Beyotime) and $1 \mathrm{mg} / \mathrm{ml}$ propidium iodide (Beyotime) at $37^{\circ} \mathrm{C}$ for $30 \mathrm{~min}$. Cell cycle was performed by flow cytometry (BD Biosciences, San Jose, CA, USA).

Colony formation assay. Cells were seeded into a six-well plate (200 cells per well). Cells were cultured at $37^{\circ} \mathrm{C}$ with $5 \%$ $\mathrm{CO}_{2}$ for 14 days until the clones were visible to the naked eye. Thereafter, the medium was removed and the cells were fixed with $4 \%$ paraformaldehyde, dyed with crystal violet. Under a microscope (Olympus, Tokyo, Japan) stained clones with cell number $>50$ were counted and digital images were taken.

Immunofluorescence (IF). Cells grown on cover slips were fixed with $4 \%$ paraformaldehyde for $15 \mathrm{~min}$ at room temperature. Then the cells were permeabilized with $0.1 \%$ Triton-X-100 solution for $30 \mathrm{~min}$. After washing with PBS, cells were blocked with $10 \%$ goat serum for $15 \mathrm{~min}$ at room temperature. Then, cells were incubated with mouse monoclonal antiPCNA (1:50) in PBS with $10 \%$ goat serum at $4^{\circ} \mathrm{C}$ overnight. After washing with PBS three times, cells were incubated with Cy3-conjugated anti-mouse secondary antibodies for $1 \mathrm{~h}$ at room temperature. The nuclei were counterstained with DAPI (Biosharp, Seattle, WA, USA). Under a magnification of x400, fluorescence images of 5 different microscopic fields were captured by a fluorescence microscope.

Wound healing assay. Cells were seeded in 12-well plates and incubated until $>80 \%$ confluence. A straight wound was created by scratching with a $200-\mu 1$ pipette tip. Floating cells were removed by washing with serum-free medium twice. The cells were then cultured in serum-free medium and allowed to migrate into the wound area. Images of the migrated cells were acquired with an inverted microscope (Olympus) at 0, 12, $24 \mathrm{~h}$.

Transwell invasion assay. Transwell chambers (Corning Inc., Corning, NY,. USA) were pre-coated with matrigel (BD Biosciences) at $37^{\circ} \mathrm{C}$ for $2 \mathrm{~h}$. Cells $\left(10^{4}\right)$ in $200 \mu \mathrm{l}$ serumfree medium were added to the upper compartment, and to the lower chamber was added $800 \mu \mathrm{l}$ DMEM containing $20 \%$ FBS. Then the cells were incubated for $24 \mathrm{~h}$ at $37^{\circ} \mathrm{C}$ with $5 \%$ $\mathrm{CO}_{2}$. A cotton swab was used to remove the non-invaded cells in the upper compartment. The invaded cells were fixed in $4 \%$ paraformaldehyde and stained with $0.1 \%$ crystal violet for $30 \mathrm{~min}$. Under the microscope the cells were counted in five random sights.

Gelatin zymography assay. The samples were separated in $10 \%$ SDS polyacrylamide gel containing $0.2 \%$ gelatin in ice 
A

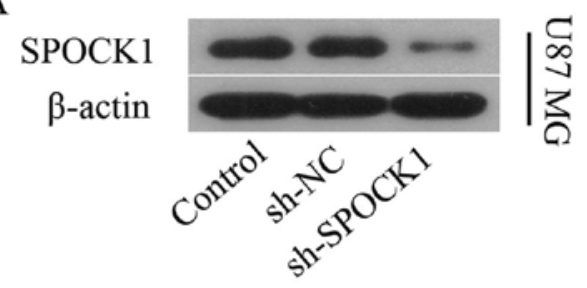

B

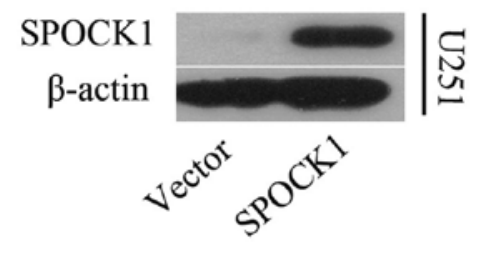

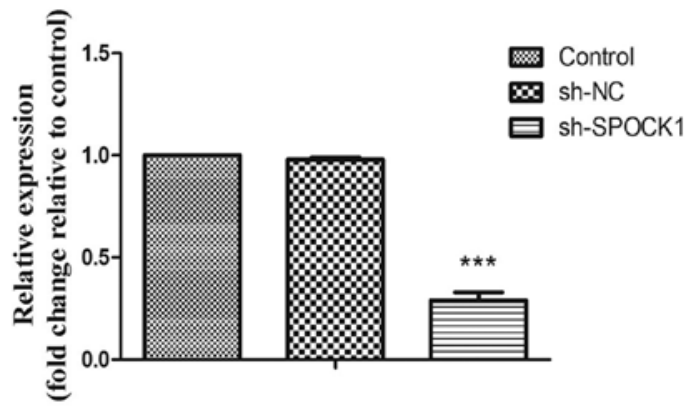

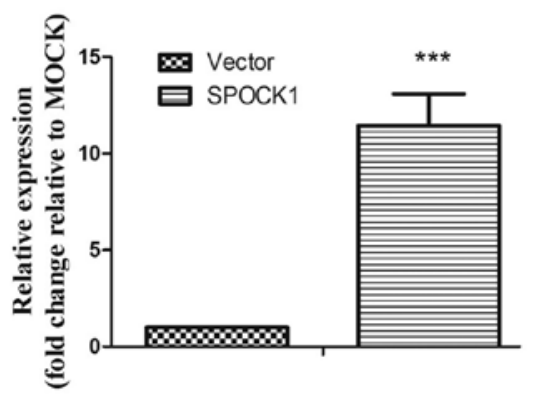

$\mathrm{C}$

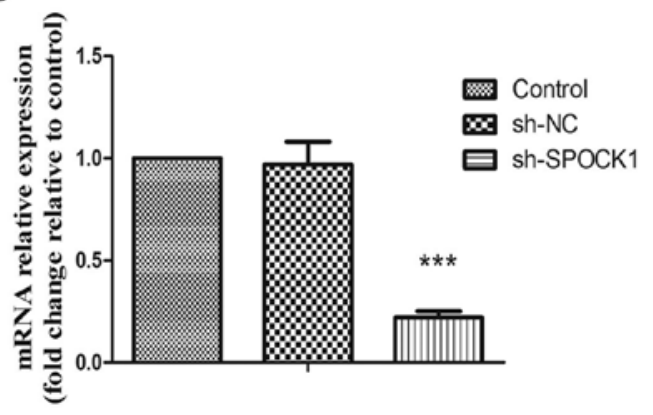

$\mathrm{D}$

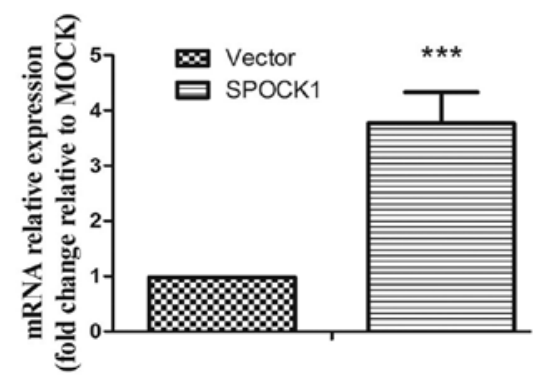

Figure 1. Plasmid mediated silencing or overexprssion of SPOCK1 in glioma cell lines. (A and B) Protein expression levels of SPOCK1 silencing in U87 MG cells and SPOCK1 overexpression in U251 cells were determined by western blot. $\beta$-actin was used as the loading control. (C and D) mRNA expression of SPOCK1 in SPOCK1 silencing U87 MG cells and SPOCK1 overexpressing U251 cells. The results shown are representative of three independent experiments. Each value is expressed as mean $\pm \mathrm{SD}(\mathrm{n}=3)$. ${ }^{* * *} \mathrm{P}<0.001$, versus the $\mathrm{NC}$ or vector group.

bath for $2.5 \mathrm{~h}$. Then the gels were washed in eluent buffer (2.5\% Triton X-100, $50 \mathrm{mM}$ Tris- $\mathrm{HCl}, 5 \mathrm{mM} \mathrm{CaCl} \mathrm{m}_{2}, 1 \mu \mathrm{M}$ $\mathrm{ZnCl}_{2}, \mathrm{pH}$ 7.6) for $40 \mathrm{~min}$, twice; equilibrated in developing buffer (50 mM Tris-HCl, $5 \mathrm{mM} \mathrm{CaCl}, 1 \mu \mathrm{M} \mathrm{ZnCl}_{2}, \mathrm{pH} 7.6$ ) for $20 \mathrm{~min}$, twice; and finally put in incubation buffer $(50 \mathrm{mM}$ Tris- $\mathrm{HCl}, 5 \mathrm{mM} \mathrm{CaCl}_{2}, 1 \mu \mathrm{M} \mathrm{ZnCl}_{2}, 0.02 \%$ Brij, $0.2 \mathrm{M} \mathrm{NaCl}$ ) at $37^{\circ} \mathrm{C}$ for $40 \mathrm{~h}$. Then, the gels were incubated with staining buffer $(0.05 \%$ Coomassie blue G-250 in $45 \%$ methanol, $10 \%$ acetic acid, $30 \%$ methanoic acid) for $3 \mathrm{~h}$ and then washed with destaining buffer (45\% methanol, $10 \%$ acetic acid) until clear bands appeared. The images were obtained by gel imaging system (Bio-Rad, Hercules, CA, USA) and the activities of MMPs were measured by densitometric analysis.

Flow cytometry. Annexin V-FITC/PI staining was used to measure alive, apoptotic and necrotic cells. Briefly, cells were harvested, washed with PBS and stained with a mixture of $100 \mu 1$ Annexin V-FITC and PI in the dark for $15 \mathrm{~min}$. Then flow cytometry was used to classify fluorescent cells. The number of apoptotic cells was analysed by BD FACSuite software.

Hoechst 33342 staining. Hoechst 33342 staining was performed to measure apoptotic morphology. Briefly, $5 \times 10^{4}$ cells were seeded on cover slips and fixed with $4 \%$ paraformaldehyde for $20 \mathrm{~min}$ at room temperature. After washing twice with PBS, the cells were stained with Hoechst 33342 for 5 min. Fluorescent images were acquired by a fluorescence microscopy (Olympus).

Statistical analysis. All results are expressed as mean \pm standard deviation (SD). Statistical analyses were performed using Student's t-test. A p-value of $<0.05$ was set as the significance level.

\section{Results}

Expression of the SPOCK1 gene in glioma cells. To investigate the role of SPOCK1 in glioma cells, we chose U87 MG cells with higher SPOCK1 expression level for stable transfection with shRNA vector toward SPOCK1 and U251 cells, in which SPOCK1 is infrequently expressed, for stable transfection with SPOCK1 expression vector. The expression levels of SPOCK1 was measured by real-time PCR and western blot analysis. As shown in Fig. 1A and C, an efficient silencing of SPOCK1 protein and mRNA expression was shown in U87 MG cells transfected with the SPOCK1 shRNA compared with negative control group. An obvious high level of SPOCK1 protein and 
A

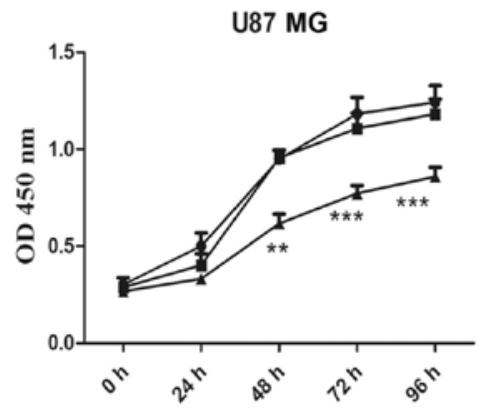

$\mathrm{B}$

U87 MG
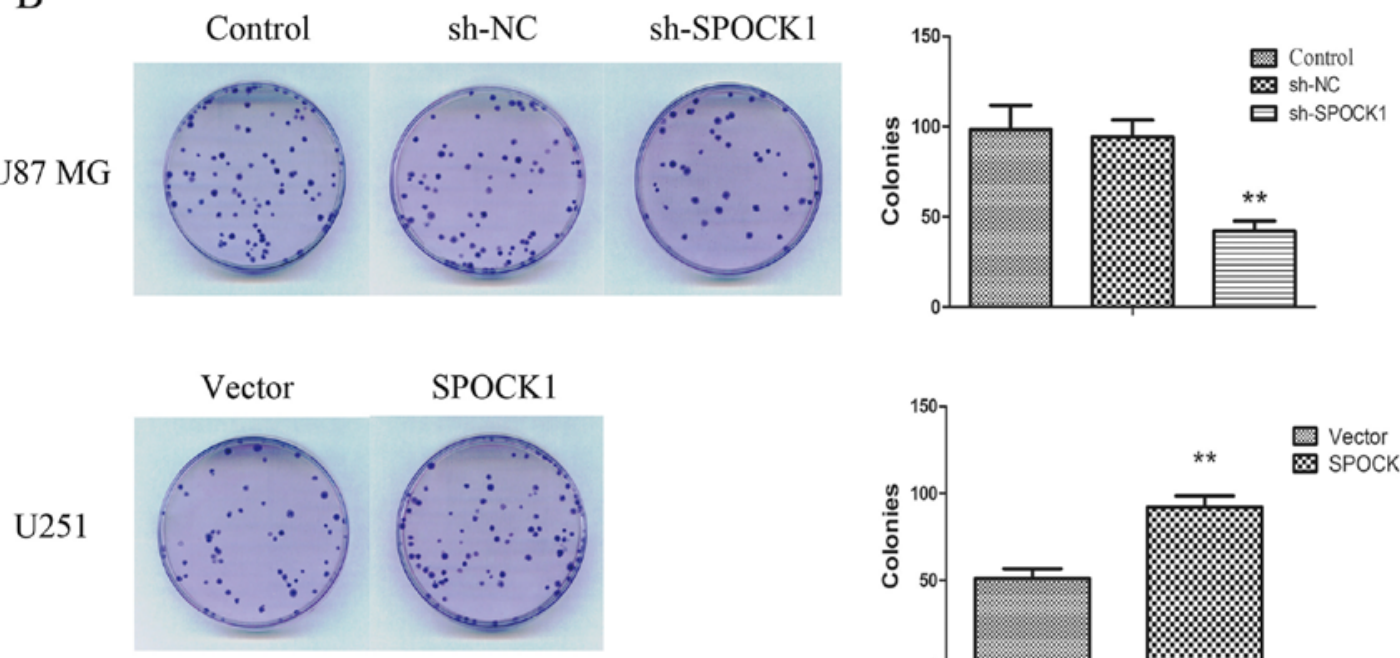

C
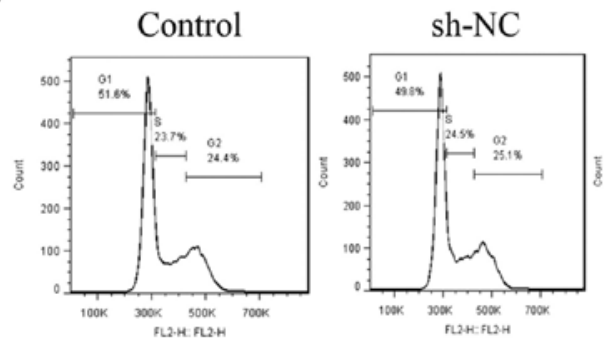

U87 MG
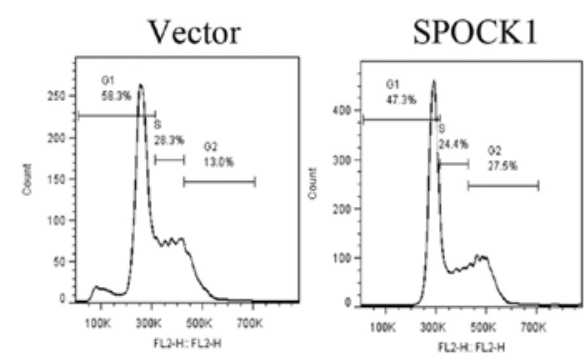

U251
U251

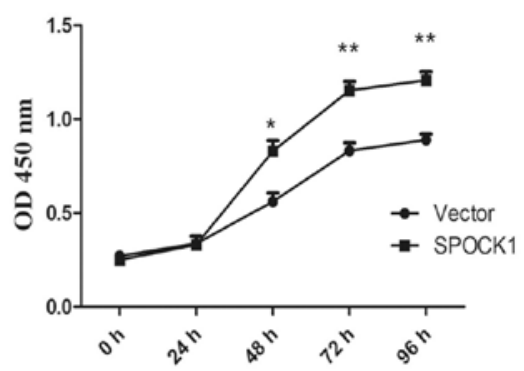



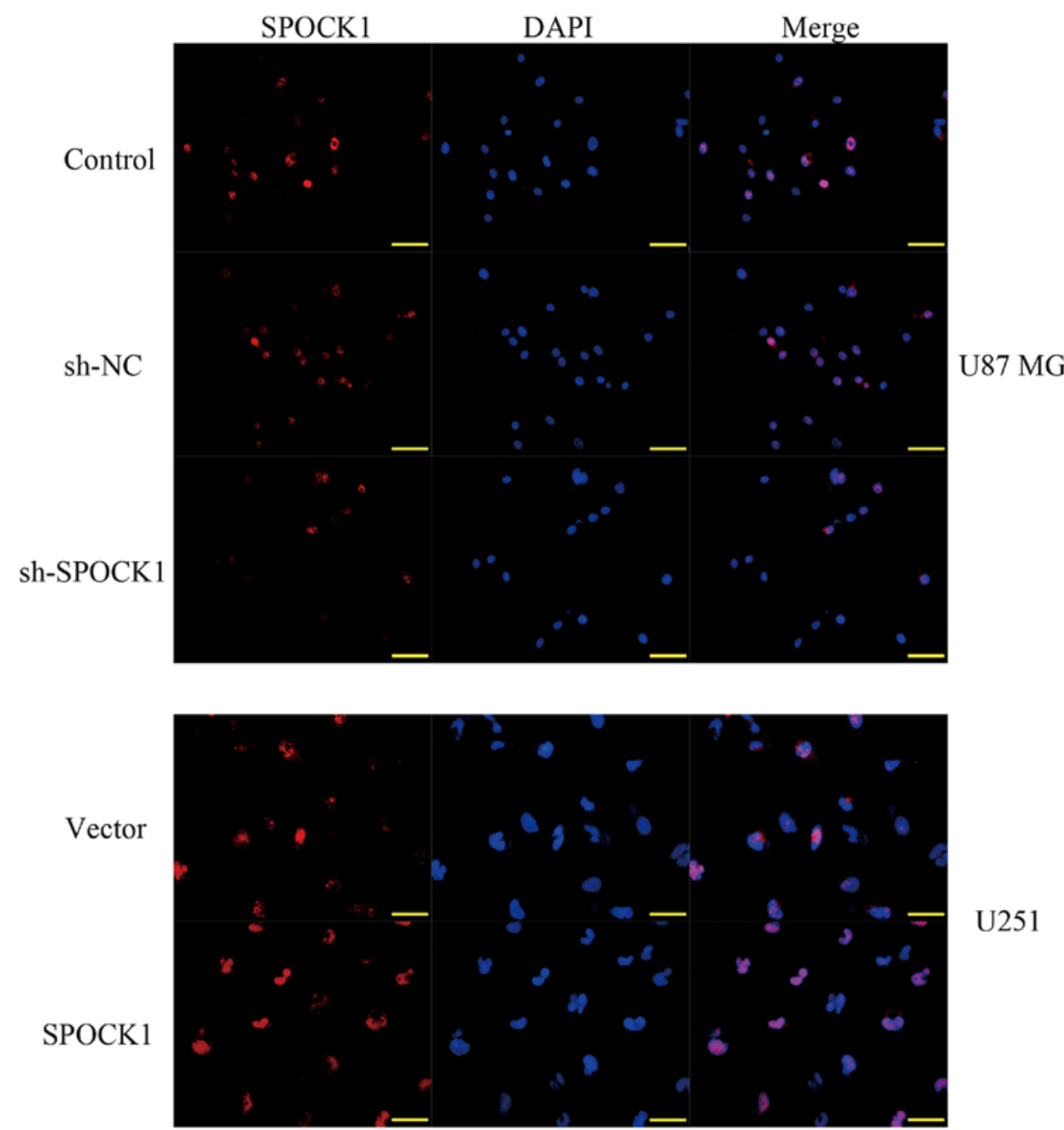

$\mathrm{U} 251$

Figure 3. The effect of SPOCK1 on PCNA expression. The expression of PCNA was determined by immunofluorescence staining (magnification, $\mathrm{x} 400)$. Scale bar in each image is $50 \mu \mathrm{m}$.

of SPOCK1, on the contrary, increasing colony formation in U251 cells. Moreover, the cell cycle progression was detected by flow cytometric analysis (Fig. 2C). The results demonstrated that silencing of SPOCK1 resulted in a larger fraction of the population in the G1 phase and a significant decrease in the proportion in $\mathrm{G} 2 / \mathrm{M}$ phase. Overexpression of SPOCK1 significantly reduced the number of cells arrested in G1 phase. Since PCNA is an index for evaluating the ability of cell proliferation, we subsequently detected the expression of PCNA by immunofluorescence assay. As shown in Fig. 3, knockdown of SPOCK1 significantly downregulated the expression of PCNA in U87 MG cells. On the contrary, overexpression of SPOCK1 upregulated the expression of PCNA in U251 cells. The above findings provide evidence that SPOCK1 as an oncogene may promote glioma cell growth.

Effect of SPOCK1 on glioma cells apoptosis. To further explore the mechanism of SPOCK1 in tumor growth, we focused on the role of SPOCK1 in cell apoptosis. As assessed by Annexin V-FITC and PI staining and shown in Fig. 4A, knockdown of SPOCK1 induced obvious apoptosis in U87 MG cells. While the apoptosis was inhibited by SPOCK1 overexpression in U251 cells. Moreover, as shown in Fig. 4B, the nuclear morphological changes in the apoptotic cells were revealed by the Hoechst 33342 staining. Silencing of SPOCK1 resulted in brighter chromatin condensation and nuclear fragmentation of the nuclei, which was significantly suppressed by SPOCK1 overexpression. To further confirm the effect of SPOCK1 on apoptosis, a number of apoptosis related proteins were determined. The results showed that knockdown of SPOCK1 induced increase in expression levels of Bax, cleaved PARP and cleaved caspase- 3 and decreased expression of Bcl-2 in U87 MG cells. The expression changes of these apoptosis related proteins were inverted when SPOCK1 was overexpressed in U251 cells. These data indicated that SPOCK1 promotes glioma cell growth by reducing cell apoptosis.

Effect of SPOCK1 on glioma cells migration and invasion. Cell migration capacity was assessed by wound healing assay. As shown in Fig. 5A, knockdown of SPOCK1 obviously inhibited the migration capacity of U87 MG cells. When SPOCK1 was overexpressed in U251 cells, the migration capacity was increased significantly. Moreover, the invasive capacity was assessed by transwell assay and shown in Fig. 5B. The results were similar to the changes in migration ability that was inhibited by SPOCK1 silencing and promoted by SPOCK1 
A
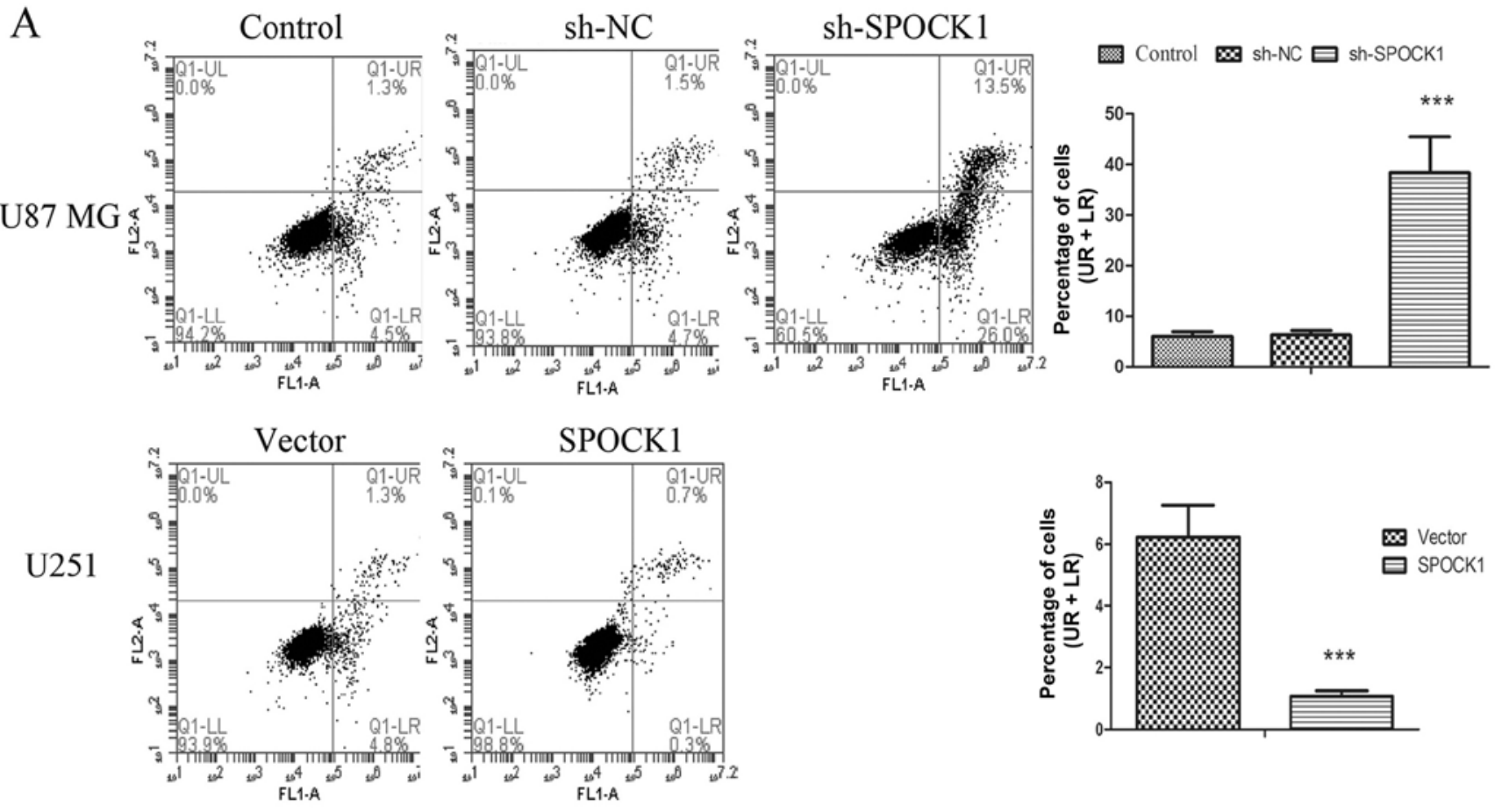

B
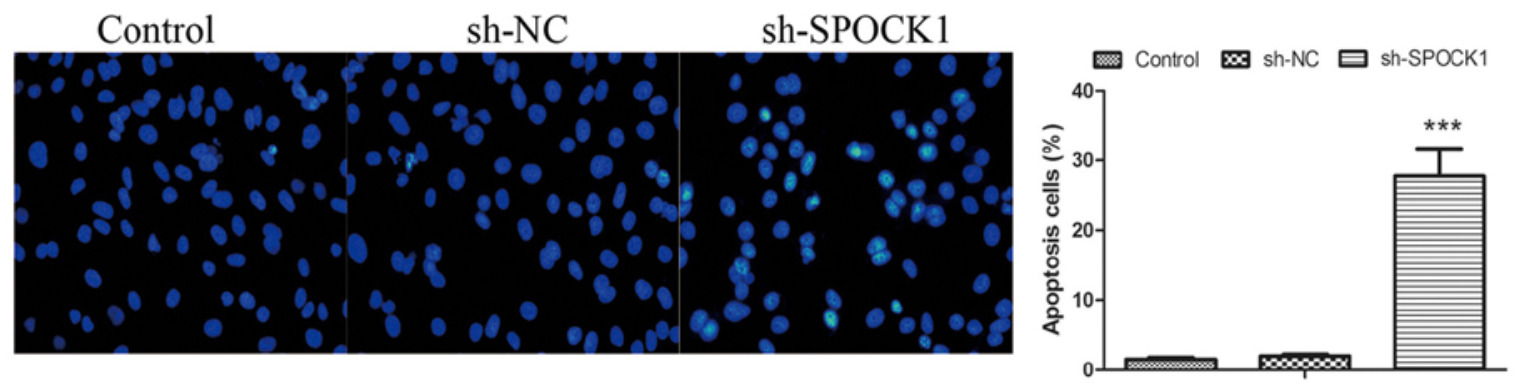

U87 MG
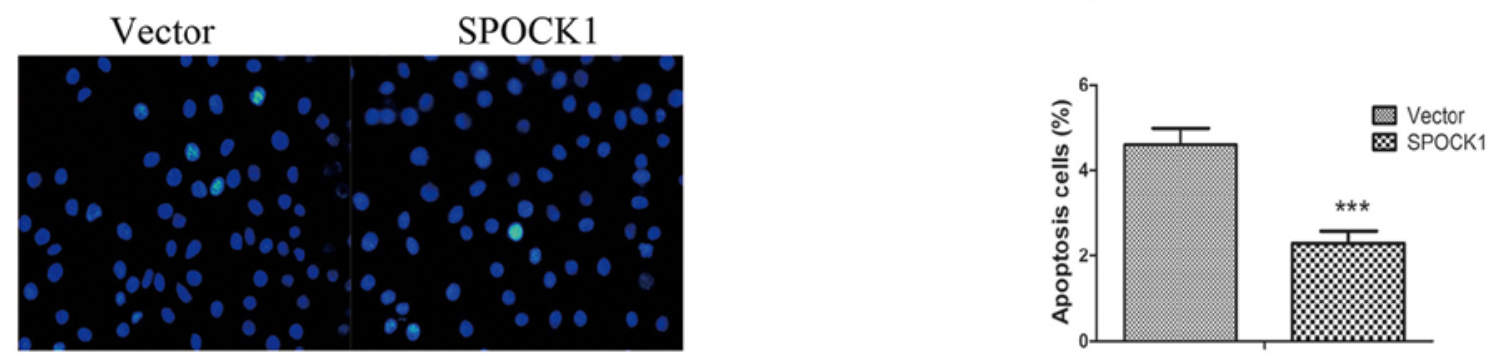

C
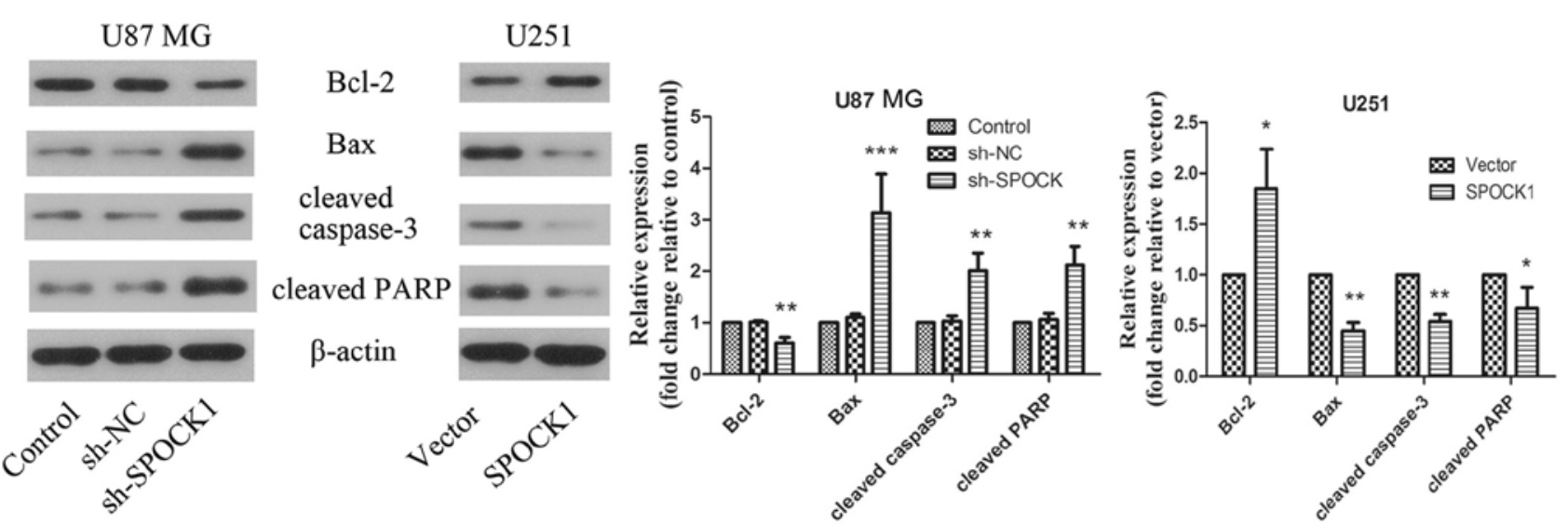

Figure 4. The effect of SPOCK1 on apoptosis of glioma cells. (A) Cell apoptosis was detected by Annexin V/PI staining using flow cytometry. The percentage of apoptotic cells are presented in the UR and LR quadrants. (B) Hoechst 33342 staining was used to display the nuclear morphological changes of the apoptotic cells. (C) Apoptosis-related proteins were detected by western blotting. $\beta$-actin was used as a loading control. The results shown are representative of three independent experiments. Each value is expressed as mean $\pm \mathrm{SD}(\mathrm{n}=3) .{ }^{.} \mathrm{P}<0.05,{ }^{* *} \mathrm{P}<0.01,{ }^{* * * *} \mathrm{P}<0.001$, versus the NC or vector group. 
A $0 \mathrm{~h}$

$12 \mathrm{~h}$

$24 \mathrm{~h}$
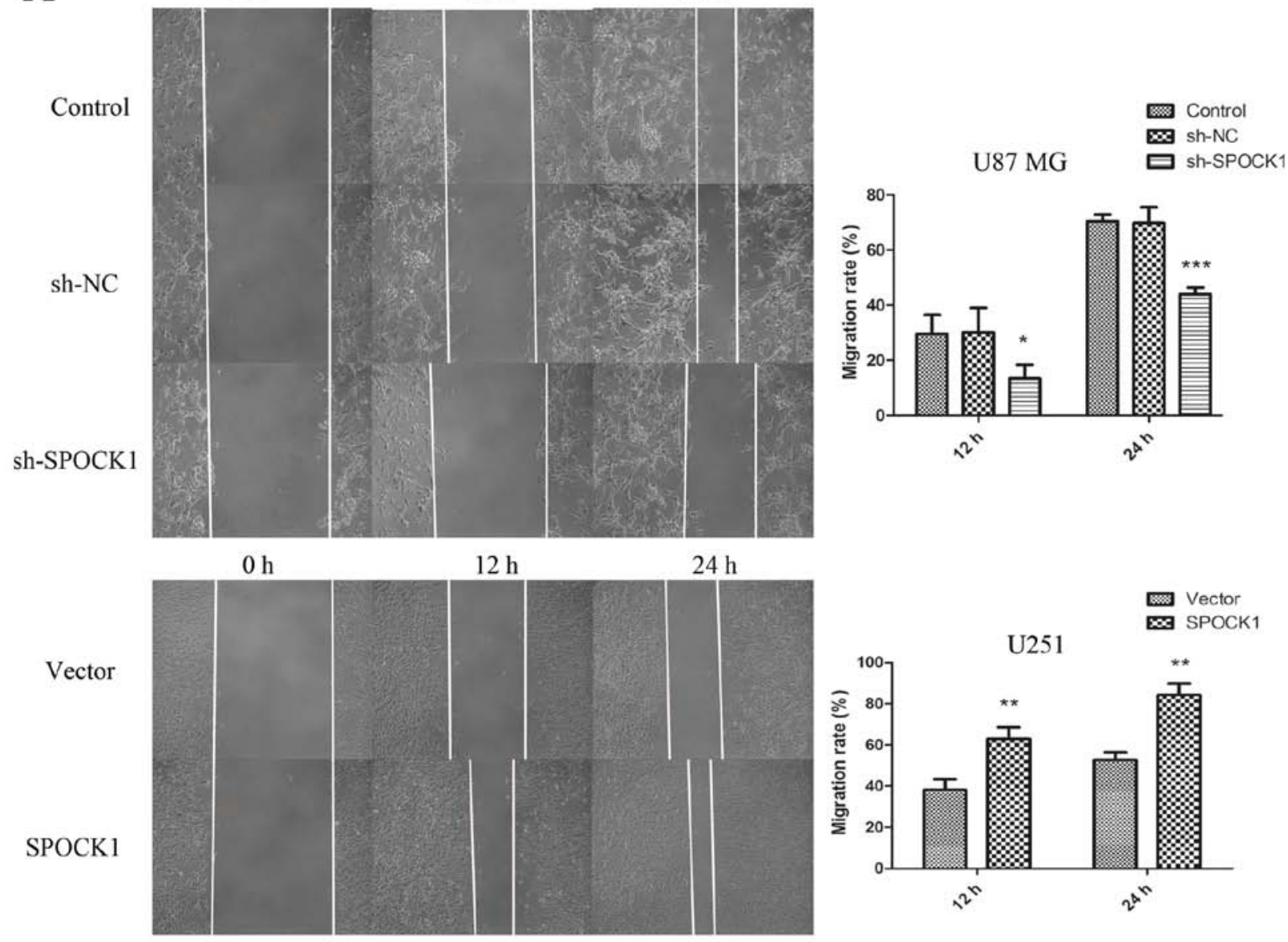

B
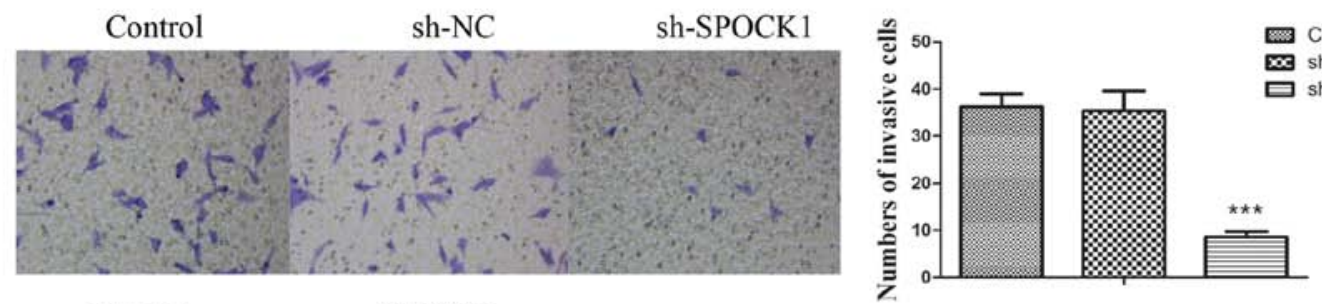

U87 MG
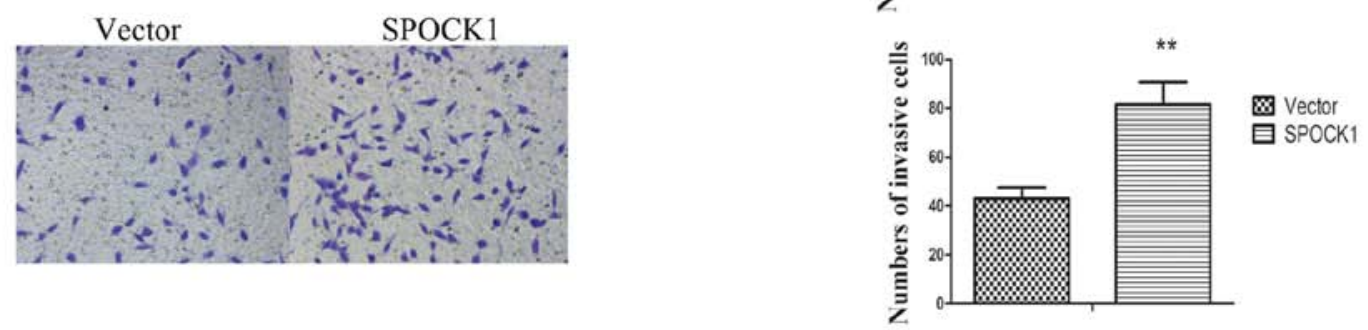

Figure 5. SPOCK1 promotes the migration and invasion of glioma cells. (A) The migration ability was determined by wound healing assay. The migration rates are shown in the column charts. (B) Transwell assay was performed to assess the invasive potency. The number of invasive cells in five random sites were counted. The results shown are representative of three independent experiments. Each value is expressed as mean $\pm \mathrm{SD}(\mathrm{n}=3)$. ${ }^{*} \mathrm{P}<0.05$, ${ }^{{ }^{* *} \mathrm{P}<0.01,{ }^{* * *} \mathrm{P}<0.001}$ versus the $\mathrm{NC}$ or vector group.

overexpression. To further confirm the effect of SPOCK1 on metastasis, the activity and expression of MMP9 and MMP2 was determined by gelatin zymography and western blotting. As shown in Fig. 6A, the activity of MMP9 and MMP2 was restrained by SPOCK1 silencing in U87 MG cells. While overexpression of SPOCK1 could promote the activity of MMP9 and MMP2. The changes of MMP9 and MMP2 expression were similar to those of MMP9 and MMP2 activity (Fig. 6B).
Effect of SPOCK1 on PI3K/AKT and Wnt/ $\beta$-catenin signaling pathways. Since PI3K/AKT and $\mathrm{Wnt} / \beta$-catenin signaling pathways are associated intimately with proliferation and metastasis of cancer cells, the effect of SPOCK1 on PI3K/AKT and Wnt/ $\beta$-catenin signaling pathways was evaluated. As shown in Fig. 7, knockdown of SPOCK1 significantly suppressed the protein levels of p-PI3K, p-AKT, Wnt and $\beta$-catenin in U87 MG cells, which could be reversed when SPOCK1 was overexpressed in U251 cells. Moreover, the 
A
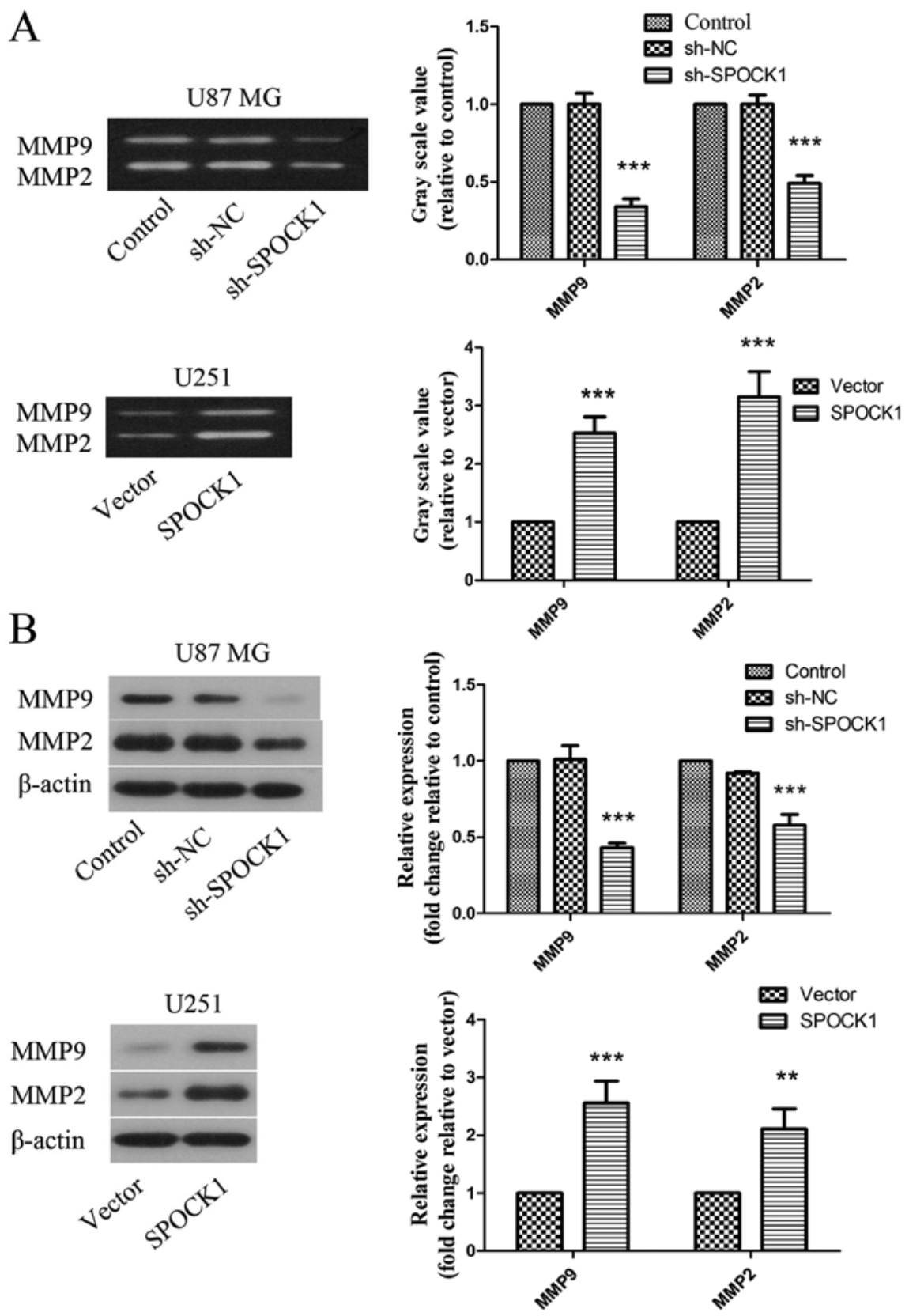

Figure 6. The effect of SPOCK1 on activity and expression of MMPs. (A) The activity of MMP2 and MMP9 was assessed by gelatin zymography assay. (B) The protein expression levels of MMP2 and MMP9 were detected by western blot. $\beta$-actin was used as a loading control. The results shown are representative of three independent experiments. Each value is expressed as mean $\pm \mathrm{SD}(\mathrm{n}=3)$. ${ }^{* *} \mathrm{P}<0.01,{ }^{* * * *} \mathrm{P}<0.001$, versus the NC or vector group.

downstream targets of $\mathrm{Wnt} / \beta$-catenin were also assessed. The results indicated that the protein levels of $\mathrm{c}-\mathrm{MYC}$ and cyclin D1 were decreased by SPOCK1 silencing, which were increased obviously when SPOCK1 was overexpressed.

\section{Discussion}

Glioma is the most common malignancy in the central nervous system, and is the most aggressive and progressive. Because of the poor prognosis and high fatality, glioma severely threatens life and health of patients. The malignant transformation of neurogliocyte and neurone is a complicated process, involving a large number of oncogenes and tumor suppressor genes. Increasing evidence has demonstrated that SPOCK1 as an oncogene promoted various cancer cell proliferation and invasion. We investigated the effect of SPOCK1 on glioma cells proliferation, migration and invasion, which provide a potential therapeutic target as well as a prognostic marker for glioma.

Malignant proliferation is one of the most significant features of tumor cells. Infinite proliferation and anti-apoptosis are two important malignant phenotypes of glioma. In the malignant process of glioma, the tumor cell density is increased with significant nuclear division and atypia $(12,13)$. In our present study, the effect of SPOCK1 on glioma cell malignant proliferation was investigated. As assayed by CCK8, the proliferation of glioma cells was obviously inhibited by SPOCK1 silencing. Then clone formation ability 


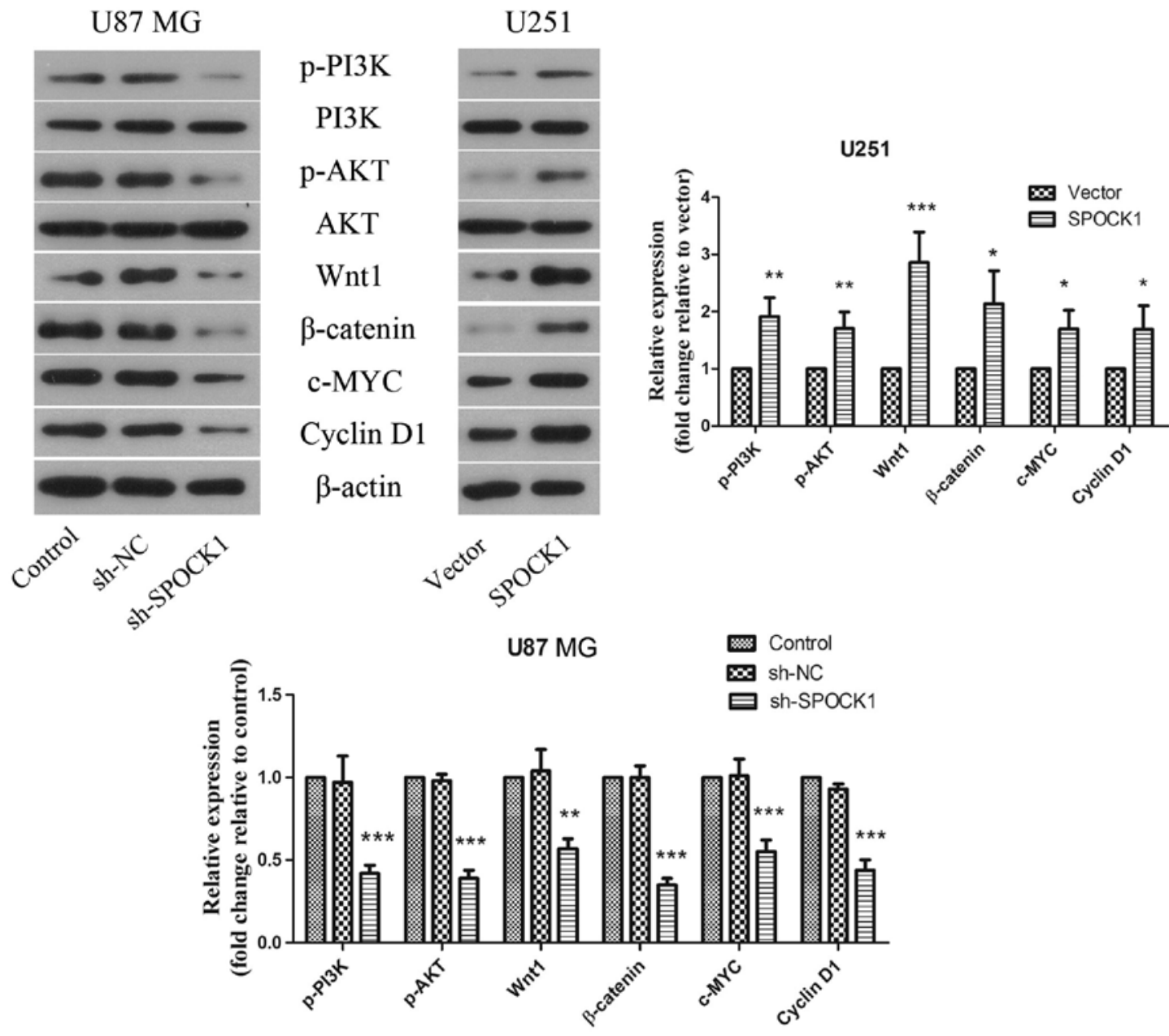

Figure 7. The effect of SPOCK1 on PI3K/AKT and Wnt/ $\beta$-catenin signaling pathways. The protein expression levels of p-PI3K, PI3K, p-AKT, AKT, Wnt, $\beta$-catenin, c-MYC, and cyclin D1 in glioma cells was detected by western blotting. $\beta$-actin was used as a loading control. The results shown are representative of three independent experiments. Each value is expressed as mean $\pm \mathrm{SD}(\mathrm{n}=3) .{ }^{*} \mathrm{P}<0.05,{ }^{* *} \mathrm{P}<0.01,{ }^{* * *} \mathrm{P}<0.001$, versus the NC or vector group.

was suppressed by SPOCK1 silencing. Finally the results of cell cycle analysis showed that there was a larger fraction of the population in the G1 phase and a significant decrease in the proportion in G2/M phase. Overexpression of SPOCK1 promoted glioma cell proliferation and clone formation, and decreased the percentage of cells in G1 phase. These results demonstrated that SPOCK1 participated in malignant progression of glioma via promoting glioma cell proliferation from positive and negative aspects.

Proliferating cell nuclear antigen (PCNA) is a nuclear protein, expressed in proliferative cells only. The synthesis of PCNA has close relation with cellular proliferation cycle, which is increased rapidly in late G1 phase and peaked in S phase. Previous research found that the level of PCNA is relative to the tumor type and clinical stage of the central nervous system tumors (14). Another study found that inhibition of PCNA could suppress DNA replication and prevent cells from going into proliferation period (15). In our present study, the expression level of PCNA was decreased by SPOCK1 silencing, while increased when SPOCK1 was overexpressed.

Apoptosis inhibition or escape is another feature of malignant tumor cells. We also observed SPOCK1 effects on the apoptosis of glioma cells. Our results indicated that knockdown of SPOCK1 induced cell apoptosis significantly, which could be suppressed by overexpression of SPOCK1. Cell apoptosis is regulated by a series of apoptosis-related genes, the most significant of which are Bcl-2 and caspase gene families. Bcl-2 is an important member of $\mathrm{Bcl}-2$ gene family and is also an apoptosis suppressor gene. Bcl-2 is expressed in brain tumors, which was significantly positively related to the degree of tumor malignancy $(16,17)$. Bax is another apoptosis gene in Bcl-2 family, which and can inhibit the anti-apoptosis effect of Bcl-2. The survival of the cells is determined by the ratio of Bcl-2/Bax $(18,19)$. Caspase-3, an executioner caspase, plays a key role in the execution phase of apoptosis by cleaving many key cellular proteins, such as PARP $(20,21)$. According to our results, silencing of SPOCK1 decreased the ratio of Bcl-2/Bax and promoted the expression of cleaved caspase- 3 and PARP. Overexpression of SPOCK1 resulted in the increased ratio of Bcl-2/Bax and lower expression of cleaved caspase-3 and PARP.

The metastasis and recurrence are the major prognostic factors of cancer patients. Metastasis refers to primary malignant tumor cells invading other parts of the body and spreading to other organs, which is one of the fundamental biologic behaviors of tumor. Multiple steps, such as migration and invasion, participate in the process of metastasis of tumors. Our results demonstrated that the migration and invasion of glioma 
cells was suppressed by silencing of SPOCK1 and promoted by SPOCK1 overexpression. Matrix metalloproteinases (MMPs), a family of endopeptidases, could degrade extracellular matrix. Recent research found that the degradation of extracellular matrix and basement membrane played key roles in the invasion and metastasis of tumor, which could be regulated by MMPs (22). Research also found that the levels of MMPs were positively related to the invasive ability of glioma cells (23). MMP2 and MMP9 are two important MMPs, the expression levels of which are enhanced in glioma cells $(24,25)$. As the glioma malignancy degree increased, the expression of MMP2 and MMP9 was increased $(23,26)$. Our results demonstrated that the activity and expression of MMP2 and MMP9 were restrained by SPOCK1 silencing, which could be promoted by SPOCK1 overexpression.

Growing evidence has demonstrated that PI3K/AKT signaling pathway played important roles in the occurrence and development of glioblastoma $(27,28)$. As one of the important intracellular signal transduction pathways, PI3K/AKT signaling pathway not only impacts on proliferation and apoptosis of cancer cells, but also has a role in chemotherapy reactions. Recent studies suggest that the inhibitors of PI3K/AKT signaling pathway could fight drug resistance of various cancers (29-31). In our present study, the protein levels of p-PI3K, p-AKT were downregulated by knockdown of SPOCK1. While overexpression of SPOCK1 could upregulate the protein levels of $\mathrm{p}$-PI3K, $\mathrm{p}-\mathrm{AKT}$. $\mathrm{Wnt} / \beta$-catenin signaling pathway is a focus of tumor biology. Increasing evidence shows that $\mathrm{Wnt} / \beta$-catenin signaling pathway is closely related to tumorigenesis. With the deepening of the research, c-MYC and cyclin D1 were found to be target genes of $\mathrm{Wnt} / \beta$-catenin signaling pathway $(32,33)$. These downstream genes were closely related to proliferation and differentiation. It was found that the activation of c-MYC played a role in various tumors, including glioma, lymphoma, lung cancer, and colorectal cancer (34-37). Research also found that c-MYC and cyclin D1 was regulated by $\beta$-catenin in ovarian cancer (38). Our present study found that the protein levels of Wnt and $\beta$-catenin were decreased by SPOCK1 silencing, and upregulated in SPOCK1 overexpression. The expression levels of c-MYC and cyclin D1 were positively correlated with $\mathrm{Wnt} / \beta$-catenin.

In conclusion, our results suggest that SPOCK1 may serve as an oncogene in glioma. Overexpression of SPOCK1 promotes glioma cell proliferation, migration and invasion via $\mathrm{PI} 3 \mathrm{~K} / \mathrm{AKT}$ and $\mathrm{Wnt} / \beta$-catenin signaling pathways, which could be reversed by SPOCK1 silencing. These observations confirm that SPOCK1 may serve as both a treatment target and prognostic indicator for patients with glioma.

\section{References}

1. Taylor LP: Diagnosis, treatment, and prognosis of glioma: Five new things. Neurology 75 (Suppl 1): S28-S32, 2010.

2. Brada M, Stenning S, Gabe R, Thompson LC, Levy D, Rampling R, Erridge S, Saran F, Gattamaneni R, Hopkins K, et al: Temozolomide versus procarbazine, lomustine, and vincristine in recurrent high-grade glioma. J Clin Oncol 28: 4601-4608, 2010.

3. Morris PG and Lassman AB: Medical oncology: Optimizing chemotherapy and radiotherapy for anaplastic glioma. Nat Rev Clin Oncol 7: 428-430, 2010.
4. Gabayan AJ, Green SB, Sanan A, Jenrette J, Schultz C, Papagikos M, Tatter SP, Patel A, Amin P, Lustig R, et al: GliaSite brachytherapy for treatment of recurrent malignant gliomas: A retrospective multi-institutional analysis. Neurosurgery 58: 701-709, discussion 701-709, 2006.

5. Sciumè G, Santoni A and Bernardini G: Chemokines and glioma: Invasion and more. J Neuroimmunol 224: 8-12, 2010.

6. Butowski NA, Sneed PK and Chang SM: Diagnosis and treatment of recurrent high-grade astrocytoma. J Clin Oncol 24: 1273-1280, 2006.

7. Song X, Han P, Liu J, Wang Y, Li D, He J, Gong J, Li M, Tu W, Yan W, et al: Up-regulation of SPOCK1 induces epithelialmesenchymal transition and promotes migration and invasion in esophageal squamous cell carcinoma. J Mol Histol 46: 347-356, 2015.

8. Miao L, Wang Y, Xia H, Yao C, Cai H and Song Y: SPOCK1 is a novel transforming growth factor- $\beta$ target gene that regulates lung cancer cell epithelial-mesenchymal transition. Biochem Biophys Res Commun 440: 792-797, 2013.

9. Li Y, Chen L, Chan TH, Liu M, Kong KL, Qiu JL, Li Y, Yuan YF and Guan XY: SPOCK1 is regulated by CHD1L and blocks apoptosis and promotes HCC cell invasiveness and metastasis in mice. Gastroenterology 144: 179-191.e4, 2013.

10. Shu YJ, Weng H, Ye YY, Hu YP, Bao RF, Cao Y, Wang XA, Zhang F, Xiang SS, Li HF, et al: SPOCK1 as a potential cancer prognostic marker promotes the proliferation and metastasis of gallbladder cancer cells by activating the PI3K/AKT pathway. Mol Cancer 14: 12, 2015.

11. Colin C, Baeza N, Bartoli C, Fina F, Eudes N, Nanni I, Martin PM, Ouafik L and Figarella-Branger D: Identification of genes differentially expressed in glioblastoma versus pilocytic astrocytoma using suppression subtractive hybridization. Oncogene 25: 28182826,2006

12. Taillibert S, Pedretti M and Sanson M: Current classification of gliomas. Presse Med 33: 1274-1277, 2004 (In French).

13. Beetz C, Bergner S, Brodoehl S, Brodhun M, Ewald C, Kalff R, Krüger J, Patt S, Kiehntopf M and Deufel T: Outcome-based profiling of astrocytic tumours identifies prognostic gene expression signatures which link molecular and morphologybased pathology. Int J Oncol 29: 1183-1191, 2006.

14. Kayaselçuk F, Zorludemir S, Gümürdühü D, Zeren $H$ and Erman T: PCNA and Ki-67 in central nervous system tumors: Correlation with the histological type and grade. J Neurooncol 57: 115-121, 2002.

15. Punchihewa C, Inoue A, Hishiki A, Fujikawa Y, Connelly M, Evison B, Shao Y, Heath R, Kuraoka I, Rodrigues P, et al: Identification of small molecule proliferating cell nuclear antigen (PCNA) inhibitor that disrupts interactions with PIP-box proteins and inhibits DNA replication. J Biol Chem 287: 14289-14300, 2012.

16. Alderson LM, Castleberg RL, Harsh GR IV, Louis DN and Henson JW: Human gliomas with wild-type p53 express bcl-2. Cancer Res 55: 999-1001, 1995.

17. Deckert-Schlüter M, Rang A and Wiestler OD: Apoptosis and apoptosis-related gene products in primary non-Hodgkin's lymphoma of the central nervous system. Acta Neuropathol 96: 157-162, 1998.

18. Rossé T, Olivier R, Monney L, Rager M, Conus S, Fellay I, Jansen B and Borner C: Bcl-2 prolongs cell survival after Bax-induced release of cytochrome c. Nature 391: 496-499, 1998.

19. Borner C: The Bcl-2 protein family: Sensors and checkpoints for life-or-death decisions. Mol Immunol 39: 615-647, 2003.

20. Porter AG and Jänicke RU: Emerging roles of caspase-3 in apoptosis. Cell Death Differ 6: 99-104, 1999.

21. Lin C, Holland RE Jr, Donofrio JC, McCoy MH, Tudor LR and Chambers TM: Caspase activation in equine influenza virus induced apoptotic cell death. Vet Microbiol 84: 357-365, 2002.

22. Brown GT and Murray GI: Current mechanistic insights into the roles of matrix metalloproteinases in tumour invasion and metastasis. J Pathol 237: 273-281, 2015.

23. Sawaya RE, Yamamoto M, Gokaslan ZL, Wang SW, Mohanam S, Fuller GN, McCutcheon IE, Stetler-Stevenson WG, Nicolson GL and Rao JS: Expression and localization of $72 \mathrm{kDa}$ type IV collagenase (MMP-2) in human malignant gliomas in vivo. Clin Exp Metastasis 14: 35-42, 1996.

24. Rao JS, Steck PA, Mohanam S, Stetler-Stevenson WG, Liotta LA and Sawaya R: Elevated levels of M(r) 92,000 type IV collagenase in human brain tumors. Cancer Res 53 (Suppl): 2208-2211, 1993. 
25. Forsyth PA, Wong H, Laing TD, Rewcastle NB, Morris DG, Muzik H, Leco KJ, Johnston RN, Brasher PM, Sutherland G, et al: Gelatinase-A (MMP-2), gelatinase-B (MMP-9) and membrane type matrix metalloproteinase-1 (MT1-MMP) are involved in different aspects of the pathophysiology of malignant gliomas. Br J Cancer 79: 1828-1835, 1999.

26. Sawaya R, Go Y, Kyritisis AP, Uhm J, Venkaiah B, Mohanam S, Gokaslan ZL and Rao JS: Elevated levels of Mr 92,000 type IV collagenase during tumor growth in vivo. Biochem Biophys Res Commun 251: 632-636, 1998.

27. Ströbele S, Schneider M, Schneele L, Siegelin MD, Nonnenmacher L, Zhou S, Karpel-Massler G, Westhoff MA, Halatsch ME and Debatin KM: A Potential role for the inhibition of PI3K signaling in glioblastoma therapy. PLoS One 10: e0131670, 2015.

28. Jiao Y, Li H, Liu Y, Guo A, Xu X, Qu X, Wang S, Zhao J, Li Y and Cao Y: Resveratrol inhibits the invasion of glioblastomainitiating cells via down-regulation of the PI3K/Akt/NF- $\mathrm{BB}$ signaling pathway. Nutrients 7: 4383-4402, 2015.

29. Shi L, Fei X, Wang $Z$ and You Y: PI3K inhibitor combined with miR-125b inhibitor sensitize TMZ-induced anti-glioma stem cancer effects through inactivation of $\mathrm{Wnt} / \beta$-catenin signaling pathway. In Vitro Cell Dev Biol Anim 51: 1047-1055, 2015.

30. Geuna E, Milani A, Martinello R, Aversa C, Valabrega G Scaltriti $\mathrm{M}$ and Montemurro F: Buparlisib, an oral pan-PI3K inhibitor for the treatment of breast cancer. Expert Opin Investig Drugs 24: 421-431, 2015.

31. Ku BM, Jho EH, Bae YH, Sun JM, Ahn JS, Park K and Ahn MJ: BYL719, a selective inhibitor of phosphoinositide 3-Kinase $\alpha$, enhances the effect of selumetinib (AZD6244, ARRY-142886) in KRAS-mutant non-small cell lung cancer. Invest New Drugs 33: 12-21, 2015.
32. Brabletz T, Herrmann K, Jung A, Faller $\mathrm{G}$ and Kirchner T: Expression of nuclear beta-catenin and c-myc is correlated with tumor size but not with proliferative activity of colorectal adenomas. Am J Pathol 156: 865-870, 2000.

33. Yang N, Wang Y, Hui L, Li X and Jiang X: SOX 1, contrary to SOX 2, suppresses proliferation, migration, and invasion in human laryngeal squamous cell carcinoma by inhibiting the Wnt/ $\beta$-catenin pathway. Tumour Biol 36: 8625-8635, 2015.

34. Lee KS, Kwak Y, Nam KH, Kim DW, Kang SB, Choe G, Kim WH and Lee HS: c-MYC Copy-Number Gain Is an Independent Prognostic Factor in Patients with Colorectal Cancer. PLoS One 10: $\mathrm{e} 0139727,2015$.

35. Leone A, Roca MS, Ciardiello C, Terranova-Barberio M, Vitagliano C, Ciliberto G, Mancini R, Di Gennaro E, Bruzzese F and Budillon A: Vorinostat synergizes with EGFR inhibitors in NSCLC cells by increasing ROS via up-regulation of the major mitochondrial porin VDAC1 and modulation of the c-Myc-NRF2KEAP1 pathway. Free Radic Biol Med 89: 287-299, 2015.

36. Ouyang Q, Chen G, Zhou J, Li L, Dong Z, Yang R, Xu L, $\mathrm{Cui} \mathrm{H}, \mathrm{Xu} \mathrm{M}$ and Yi L: Neurotensin signaling stimulates glioblastoma cell proliferation by upregulating c-Myc and inhibiting miR-29b-1 and miR-129-3p. Neuro Oncol 18: 216-226, 2016.

37. Suk FM, Lin SY, Lin RJ, Hsine YH, Liao YJ, Fang SU and Liang YC: Bortezomib inhibits Burkitt's lymphoma cell proliferation by downregulating sumoylated hnRNP K and c-Myc expression. Oncotarget 6: 25988-26001, 2015.

38. Fu Q, Chen Z, Gong X, Cai Y, Chen Y, Ma X, Zhu R and Jin $\mathrm{J}$ : $\beta$-Catenin expression is regulated by an IRES-dependent mechanism and stimulated by paclitaxel in human ovarian cancer cells. Biochem Biophys Res Commun 461: 21-27, 2015. 